Geometrical aspects of general relativity

Gravitational Curvature: An Introduction to Einstein's Theory. By Theodore Frankel. Pp. 172. (Freeman: San Francisco, 1979.) $£ 5.20$.

TEXTBOOKS on general relativity fall roughly into two classes - the geometrical and the physical. As an example of the former class we have J. L. Synge's fine book Relativity: The General Theory (North-Holland: Amsterdam); and in the latter class there is S. Weinberg's excellent Gravitation and Cosmology (Wiley: New York). Theodore Frankel's book falls squarely into the geometrical division, as suggested by his title.

Gravitational Curvature starts with a short chapter on special relativity which does no more than set the scene for what is to follow. In chapters 2 and 3 Einstein's equations are approached through the principle of equivalence, the gravitational red shift and Poisson's equation. It is in the essence of the author's treatment that Poisson's rather than Laplace's equation should appear at this stage because throughout he is as much interested in the right-hand side of Einstein's equations

$$
R_{i k}-\frac{1}{2} g_{i k} R=8 \pi x T_{i k}
$$

as he is in the left, an attitude which is still fairly uncommon.

It is in chapter 4 that the author declares his hand, in a section headed "A Geometric Form of Einstein's Equations", where he rewrites (1) as

$$
8 \pi x T(\zeta, \zeta)=-\frac{1}{2} \varepsilon_{\zeta} R_{V^{3}}+\operatorname{tr}\left(\mathbf{b}_{\Lambda} \mathbf{b}\right) .
$$

Here $\zeta$ is a unit vector at a point $p$ in space-time $V^{4}$, and $V^{3}$ is any hypersurface normal to $\xi ; R_{V^{3}}$ is the scalar curvature of $V^{3}$, and $\operatorname{tr}(\mathbf{b} \wedge \mathbf{b})$ depends on the extrinsic curvature of $V^{3}$ embedded in $V^{4}\left(\varepsilon_{\zeta}\right.$ is \pm 1$)$. What (2) says is that however $V^{3}$ may curve at $p$, the left hand side (which in an older notation is $8 \pi x T^{i k} \zeta_{j} \zeta_{k}$ ) depends only on the normal $\zeta$. As an application consider a perfect fluid and let $V^{3}$ be a totally geodesic space-like hypersurface (that is, one whose second fundamental form vanishes). The second term on the right of (2) disappears and we have

$$
R_{V^{3}}=16 \pi x e
$$

Q being the proper density, which, as the author remarks, is a particularly beautiful consequence of Einstein's equations.

The author has not derived (2) just for fun. On the contrary, he uses this form of the equations repeatedly - to derive the Schwarzschild exterior solution in chapter 5 , for the general static spherical mass distribution in chapter 11 , for cosmology in chapter 12, and for other applications. In the remaining chapters are treated the perfect fluid, equations of motion, light rays, and, in some detail, electromagnetism in special and general relativity.

The treatment throughout is quite advanced. No introduction to tensor calculus or differential geometry is given, and there are no examples or exercises to help the student. Not merely is a knowledge of tensors assumed, but the reader is expected to be acquainted with differential forms, and the index-free notation as in (2) above. Gravitational Curvature is therefore not really a textbook. The author writes in the Preface that "ideally, the material here would be given as the third quarter of a year course

\section{Fludd debates}

Robert Fludd: Hermetic Philosopher and Surveyor of Two Worlds. By J. Goodwin. Pp. 96. (Thames and Hudson: London, 1979.) Paperback $£ 2.95$.

CHIEFLY remembered today as the target of polemical attacks by seventeenthcentury men of science like Kepler, Mersenne and Gassendi, Robert Fludd (1594-1637) was among the most famous physicians and occultists of his time. In an interesting paper, published in English translation in 1955 ('The Influence of Archetypal Ideas on the Scientific Theories of Johannes Kepler'), the physicist Wolfgang Pauli showed that the Fludd-Kepler debate could not simply be regarded as one between an obscurantist occultist and a modern 'scientist'. The polemic of Mersenne and Gassendi more directly rejected Fludd's ideas in the light of the corpuscularian and mechanistic philosophies then being developed. However obscure and repellent they may now seem, some grasp of Fludd's doctrines is essential for a genuine historical understanding of an influential current which

\section{Biological foundations of sensory processing}

Sensory Processing, Perception, and Behaviour. By R. B. Livingston. Pp. 106. (Raven: New York, 1978.) Paperback $\$ 11.05$.

IN his preface to this mercifully slim volume, which was aimed originally at psychiatrists, the author says his intention is "to present the main biological foundations for perception, judgement, and behavior, in an evolutionary and devoted to manifolds and Riemannian geometry", but it seems to me that the first two quarters of such a course would be pretty indigestible.

Who then will benefit from the book? I believe that to trained relativists it should cast a refreshing new light on the geometry of their subject. It would be nice to think that there will be some enlightenment passing in the other direction, by which I mean that differential geometers looking at the book may see how close relativity is to their subject, and even turn their attention to it for a while.

W. B. Bonnor

W. B. Bonnor is Professor of Mathematics at Queen Elizabeth College, University of London, UK.

was to be vanquished and eclipsed by the science of Galileo and Descartes.

Fludd's works are rare and have become expensive collectors' items chiefly for the beautiful engravings with which they were adorned by de Bry and Matthieu Merian in their sumptuous Frankfurt editions. A study of the engravings is essential for making it possible to penetrate Fludd's strange and fantastic cosmology. That has been made much easier by Dr Joscelyn Goodwin, a musicologist, who has brought together 120 of the plates in a well-printed and reasonably priced book.

According to Dr Goodwin in his biographical introduction, the chief value of his collection of engravings lies in reminding us "of the possibility, indeed the imminence, of a cosmic view free alike of the myopia of materialism and the absurdities of naive spiritualism'. But his full bibliography will usefully guide the reader to other recent sources in which an attempt has been made to place the Fludd debates within the scientific and philosophical milieu of the seventeenth century.

P. M. Rattansi

P. M. Rattansi is Professor of the History and Philosophy of Science at University College, London, UK.

developmental context.". The ground is covered in 83 pages, but the ride is uncomfortably rough.

The book is extraordinarily hard to read, and I had great difficulty in making sense of parts of it. The principal problem is the pretentious prose, which actively hinders comprehension. Here are two representative samples: "Humankind is presently in need of experiencing unprecedented perceptual, judgemental, and behavioral discontinuity, from prior to new forms of imaging"; and "similarity of views are attractive to one another, leading to greater introversion of perspectives and greater societal selfrighteousness". 